\title{
Disjunçóes legais e institucionais da política metropolitana e da politica nacional de desenvolvimento regional
}

Joáo Mendes da Rocha Neto. Universidade de Brasília, Brasília, Brasil. Adriana Melo Alves. Ministério do Planejamento, Orçamento e Gestão, Brasília, Brasil.

REsumo | O debate em torno dos recortes territoriais definidos pela Política Nacional de Desenvolvimento Regional e suas relaçóes com as Regióes Metropolitanas brasileiras no contexto da política tem se mostrado contraditório com um claro afastamento de dois espaços que naturalmente estão conectados. É essa dimensão paradoxal que o presente artigo procura analisar buscando demonstrar os prejuízos dessa disjunção, sobretudo para os municípios periféricos que integram as metrópoles brasileiras. Para atingir tal objetivo, se fez necessário uma revisão teórica em alguns temas transversais as questóes espaciais e de políticas públicas, bem como um trabalho de coleta e análise de dados que permitiram chegar às conclusôes apresentadas no trabalho e tecer consideraçôes, ainda não conclusivas sobre a relação e importância das RM’s no contexto de uma política de desenvolvimento para o país.

PALAVRAS CHAVES | política regional, política urbana, áreas metropolitanas.

ABSTRACT | The debate on priority areas defined by the National Policy for Regional Development and its relations with the Brazilian Metropolitan Regions in the context of politics has shown contradictory with a clear separation of two spaces that are naturally connected. It is this paradoxical dimension that this article seeks to analyze as to demonstrate the damage this disjunction, especially for peripheral municipalities of the Brazilian metropolis. For this, it contains a theoretical revision about space issues and public policies, and also a collection work and analyzes of data that had allowed to arrive the conclusions presented in this article and to bring some points to the discussion, still not conclusive, about the metropolitan regional relation and importance in the country's development policy.

KEY WORDS | regional policy, urban policy, metropolitan areas. 


\section{Introduçáo}

Em fevereiro de 2007, o Presidente Luiz Inácio Lula, assinou o Decreto n 6.047, que institucionalizou a Política Nacional de Desenvolvimento Regional - PNDR. A edição do Decreto atende ao inciso III do Artigo 3 da Constituição Federal, o qual dispôe que entre os objetivos fundamentais da Republica está a: “(...) redução das desigualdades regionais".

Entre os dispositivos do referido Decreto, há um que se reporta as escalas espaciais de atuação prioritária da política. Consta ainda, a metodologia que elege as microrregióes (MRG's), do Instituto Brasileiro de Geografia e Estatística (IBGE) como recorte espacial para aplicar a classificação em MRG's de alta renda, MRG's de media renda e dinâmicas, MRG's de media renda estagnadas e MRG's de baixa renda. De acordo com essa classificação o conjunto de políticas que objetiva o desenvolvimento regional não se aplicaria àquelas áreas classificadas como alta renda. Cabe ressaltar que, tal distinção no âmbito da PNDR busca diminuir as desigualdades regionais encontradas no território brasileiro, explicitando que não se trata de uma política de combate a pobreza, trata, portanto de atuar em "regióes que, por situação de debilidade econômica e estagnação, geram expressivos fluxos migratórios (...) A PNDR focaliza a causa da desigualdade e da pobreza em sua expressão territorial” (Brasil, Ministério da Integração Nacional, s/d, p. 11).

A política representa um avanço no trato da questáo regional brasileira, pois rompe com a discussão macrorregional que caracterizou a historia da temática no país e reconhece que as diferenciaçóes resultam de múltiplos processos e, portanto, se manifestam em múltiplas escalas também, sobretudo, no interior das grandes regiôes brasileiras.

Entretanto, ao recortar na escala microrregional, sobretudo nas áreas metropolitanas se perdem as características dos municípios periféricos que nem sempre se encontram no mesmo nível de desenvolvimento e de produçáo de riqueza das cidades principais. Dessa forma, a PNDR, portanto, passa ao largo da problemática desses municípios que sofrem a concorrência intensa dos municípios nucleares na disputa por recursos públicos e na captação de investimentos privados.

Esse pouco diálogo da PNDR com a questão metropolitana, no entanto, resulta da ausência de políticas públicas urbanas que tenham essa escala de atuação e vice versa. As escalas de referência espacial das políticas públicas no Brasil sempre se pautaram pelo macro (grandes regióes ou até mesmo o território como um todo) ou pelo o micro (o município). Apesar dos avanços recentes da legislaçáo que tratam da questáo urbana - Lei $n^{\circ} 10.257 / 01$ e a Lei $n^{\circ} 13.089 / 15$ - ainda não conseguem enfrentar os muitos desafios que se colocam, considerando a dinâmica (interna e externa) desses organismos, suas particularidades, bem como das relaçóes que estabelecem com seus sistemas regionais.

É, portanto, essa questão que nos propomos tratar no presente artigo ao fazer uma análise dos limites existentes e possibilidades que se abrem a fim de ajustar a classificação dos municípios metropolitanos, no âmbito da PNDR, sem a pretensão de esgotar o assunto nem o processo de aperfeiçoamento da política. 
Para tanto, recorremos aos teóricos que tratam das questóes espaciais, incorporamos a discussão metropolitana, bem como, as políticas públicas e seus recursos/ instrumentos de formulação. Utilizamos, também, as bases de dados da Secretaria de Políticas de Desenvolvimento Regional (SDR) do Ministério da Integração Nacional, do IBGE e do Instituto de Pesquisa Econômica Aplicada (IPEA), para que possamos chegar as nossas consideraçôes. Houve uma análise sobre a legislação mencionada para entender onde tais diplomas legais se aproximam e onde se tornam disjuntos evidenciando lacunas de atuação institucional. Trata-se, enfim, de um trabalho que promove uma tentativa de aproximação dos aportes teóricos com a instrumentalização que dá base a política.

$\mathrm{O}$ artigo se estrutura partindo da problemática espacial e das escalas no âmbito das políticas públicas, posteriormente se detém na discussão da diferenciação interna encontrada no espaço metropolitano, na seção subseqüente procura associar questóes do planejamento em escala regional ao recorte metropolitano, logo após busca evidenciar que os municípios metropolitanos carecem de um tratamento nas políticas públicas e finaliza com um breve debate sobre os avanços recentes nesse diálogo e os desafios ainda persistentes.

\section{A problemática espacial e as escalas: o dilema das políticas públicas}

Desde sua origem a Geografia, assim como outras ciências sociais, tem se deparado com um problema ao analisar os fenômenos espaciais: as escalas. Neste sentido, Haesbaert (2002), traz uma importante contribuição:

... é importante diferenciar pelo menos duas forma de interpretar o conceito de escala: para alguns partidários de uma visão de espaço e tempo absolutos, homogêneos e estáveis, a escala pode ser reduzida à dimensão física, estanque e quantificável, do real; para outros, que vêem o espaço e o tempo como relativos, instáveis e qualitativamente heterogêneos, a escala expressa esta dimensão relativa, mutável, do real (p. 104)

No passado o processo de depuração e explicação dos fenômenos era menos complexo, uma vez que a dinâmica sócio-espacial possuía um tempo mais lento e, portanto, as representaçóes dos fenômenos e escalas de analises eram mais simples.

Assim, a questão das escalas tinha maior permanência no tempo e no espaço, uma vez que esses fenômenos se revestiam de certa "estabilidade". Sob tal questáo Haesbaert (2002), cita o esforço do geógrafo francês Yves Lacoste (1998) para o debate em torno das escalas, construindo o conceito de "espacialidade diferencial" ou "ordens de grandeza": " enfatizando que o conhecimento de um fenômeno só pode se dar pela imbricação de diferentes escalas/níveis de análise" (Lacoste, p. 105).

À medida que o mundo foi se modificando e processos complexos se manifestaram, as escalas de análise desses diferentes processos, também se viram obrigadas a mudar e reconhecer que cada vez mais é necessária uma aproximação dessa dinâmica espacial. Logo, essas diferentes escalas, mesmo quando, investigam um mesmo fenômeno, podem modificar-se nas suas formas de representá-lo, refletindo-se na sua análise. Isso porque, 
Para diferenciarmos a interpretação geográfica da simples descrição cartográfica, devemos conceber um 'conteúdo', um caráter minimamente conceitual (e não puramente descritivo) a esta escala - inserir (...) o caráter da dinâmica (política, econômica, cultural) que a regiáo envolve, o que exclui a definição de limites estanques. (Haesbaert, 2002, p. 104)

Por outro lado, a associaçáo de um número cada vez mais amplo de fatores e processos dificulta explicaçóes reducionistas e torna complexa a análise espacial e sua consequente representação, inclusive para elaboração de políticas públicas. Neste sentido, Santos (2002) citando Ruelan, aponta que:

... a geografia é uma ciência que procura definir as associações de fatos na sua forma sintética, para melhor apreender suas relaçôes complexas, isto é, para compreender um conjunto coerente de manifestaçôes da vida física e humana na superfície do globo. Convém pois, marcar com precisáo a extensäo dos fenômenos que entram na sua composiçấo de um meio geográfico, procurar suas causas e consequências e traçar sua evolução. (p. 145; grifo nosso)

Logo, esse conjunto de acontecimentos, fenômenos e processos, refletido nas escalas, evidencia que já não se pode expressá-los isoladamente sem considerar suas conexóes com espaços que lhes são exteriores. ${ }^{1}$ Esse cenário se acentua na atualidade, com a globalização/internacionalização do sistema capitalista que tem gerado forte interdependência entre Estados nacionais e regióes dispersas por todo globo terrestre.

E esses múltiplos recortes, ganham complexidade, não somente em decorrência dos processos, como já afirmado, mas também, em face das diferentes formas de enfrentamento que tem essas questóes, no âmbito do Estado e de seu alcance na dinâmica da sociedade. Quanto maior for a arena de embates e o escopo programático da política pública, mais complexa se mostrará suas relaçóes com o espaço social e mais difícil será representá-lo. Logo como afirma Lefebvre, citado por Soja:

O espaço não é um objeto cientifico afastado da ideologia e da política: sempre foi político e estratégico. Se o espaço tem uma aparência de neutralidade e indiferença em relação aos seus conteúdos e, desse modo, parece ser puramente formal, a epítome da abstração racional, é precisamente por ter sido ocupado e usado, e por já ter sido foco de processos passados cujos vestígios nem sempre são evidentes na paisagem. (Soja, 1993, p. 145)

Assim, os critérios e objetivos propostos, no âmbito de uma política pública se refletem diretamente nos seus recortes espaciais, desde que sua ação seja territorial. Esse movimento é processual, considerando que os problemas evoluem e a atuação do poder público pode modificar seus recortes geográficos prioritários, bem como o objeto dessas políticas públicas. Assim, a formulação de políticas públicas, tem sido objeto de recortes espaciais diferenciados variando de acordo com os objetos das instituiçôes e suas políticas setoriais, bem como das avaliaçôes e resultados de tais iniciativas.

1 O melhor exemplo nos é trazido por Santos (1991) citando Sorre, ao comentar sobre a gênese e funcionamento dos espaços derivados. 
No caso do Brasil, esse conjunto (disjunto) de recortes espaciais ora se justapóem, ora divergem em determinados espaços e se conflitam nas suas prioridades. Tal aspecto revela um ambiente permeado pelos sombreamentos legais e pelas vaidades institucionais, constituindo-se em um obstáculo a ser vencido na busca pela intersetorialidade das políticas públicas de foco territorial.

Ademais, os espaços de intervenção guardam dinâmicas diferenciadas e são resultantes de uma acumulação desigual de tempos. Ao utilizar a discussão de Milton Santos se verifica a importância desse entendimento para a atuação do Estado:

Desde que instalados sobre um pedaço de espaço, as variáveis (de tipos diferentes, de idades diferentes) formam (...) um fato novo, dotado da capacidade de criar e estabelecer novas relações: uma nova qualidade. Essas combinaçôes diferentes condicionam, até certo ponto, a entrada de novas variáveis. (Santos, 2002, p. 256)

Dessa forma, a intensidade de uso dessas porçóes do território vão conferir-lhes mudanças em lapsos temporais maiores ou menores, e serão percebidas nos processos de transformação espacial. No caso brasileiro, em que a urbanização e metropolização se deram de forma acelerada e concentrada, as cidades passaram a se constituir no maior e mais complexo repositório dos processos econômicos, sociais, culturais, ambientais e políticos, adquirindo enorme centralidade nos debates acadêmicos e na formulação de políticas públicas. Esse crescimento desigual dos tecidos intrametropolitanos, será objeto de debate na seção seguinte do artigo.

\section{A produçáo do espaço diferenciado nas metrópoles brasileiras}

Devemos partir do entendimento sobre o processo de urbanização, que para Manuel Castells (2000) teria dois sentidos: a concentração espacial da população, dentro de limites de dimensão e densidade; e a difusão de um sistema de valores, atitudes comportamentos denominado "cultura urbana" (p. 39).

Verifica-se, então, uma composição espacial e cultural, mediada pela economia, que se concretiza naquilo que Castells (2000) define como Urbano, entendendo-o como:

uma forma espacial de ocupação do espaço por uma população, a saber o aglomerado resultante de uma forte concentração e de uma densidade relativamente alta, tendo como correlato previsível uma diferenciação funcional e social maior. (p. 40; grifo nosso)

Salientamos os aspectos anteriores, pois é inegável o papel desempenhado pelas cidades no funcionamento da economia capitalista, como produtos e reprodutoras do sistema. Sua capacidade de protagonizar as atividades produtivas, em distintos momentos históricos, lhes permitiu essa centralidade, sobretudo, no modo de produção capitalista. Aquelas que melhor respondem tornam-se hegemônicas e tendem a concentrar poder político e econômico e passam a organizar extensos territórios segundo suas lógicas que, por sua vez, atendem as orientaçóes do sistema produtivo.

Esse mecanismo, de seletividade espacial pelo capital, leva a crescente incorporação de novas atividades a algumas dessas cidades, inclusive no espaço intra-urbano, 
originando uma espacialidade bastante complexa e diferenciada, associado a funcionalidade delas. Esse entendimento é corroborado por Castells ao dizer que a metropolização é mais ampla que o simples aumento espacial e da densidade populacional, trata-se em verdade da: “(...) difusão no espaço das atividades, das funçôes e dos grupos, e sua interdependência segundo uma dinâmica social amplamente independente da ligação geográfica (...)" (Castells, 2000, p. 53), e complementa, ao dizer que existe uma organizaçáo interna metropolitana, implicando uma interdependência hierarquizada das diferentes atividades.

Assim, compreende-se que o organismo metropolitano, alimenta, e se articula ao conjunto de mecanismos que viabilizam o capital (não somente urbano), e evidencia um modelo contraditório, incorporando atores econômicos e sociais, em uma arena de embates. Dessa forma, é possível compreender a metropolizaçáo como um processo de expansão intensiva (de concentração de renda e riqueza) e extensiva (de concentração de pobreza manifestada espacialmente) difundindo-se pelo planeta.

No entanto, não podemos entender o processo de metropolização e formação metropolitana nos diversos países como um "pastiche". Existem peculiaridades que conferem diferenciais, sobre tal aspecto, Castells (2000), em sua obra A Questão Urbana, analisa detalhadamente essas formas distintas do fenômeno metropolitano no mundo, verificando, assim que a evolução das cidades e, sua consequente metropolizaçáo. No Brasil, se manifesta diferentemente, não somente no país em relaçáo aos outros, mas entre as metrópoles brasileiras, que organizou uma rede urbana fortemente hierarquizada e concentradora da dinâmica socioeconômica do país.

Aqui não nos propomos fazer uma cronologia detalhada sobre a metropolização brasileira, a proposta é discutir que aspectos mais relevantes podem ser extraídos do processo e contribuir para o entendimento do nosso objeto de debate.

No entanto, é necessário demarcar, os anos 1930 como importantes na expansão e o crescimento industrial do país e as décadas subsequentes com a implantação de infraestrutura, que lançaram as bases do processo de urbanização no Brasil. Os Censos do IBGE apontam que em 1950 cerca de $64 \%$ da população ainda vivia no campo, passados vinte anos, o Censo de 1970 , apontava $56 \%$ da populaçáo como urbana. O quadro 1 dimensiona essa transição do Brasil rural para uma base econômica e social calcada no urbano.

Entre as muitas consequências do processo de urbanização brasileiro, a mais expressiva foi o crescimento explosivo das regióes metropolitanas. Essas cidades em face de sua importância econômica, nacional e regionalmente, passam a concentrar a geração de postos de trabalho e, consequentemente despontam como "eldorados", se constituindo em áreas receptoras de intensos movimentos migratórios.

Esse crescimento populacional demandava espaços para reprodução, sobretudo para a moradia, desses contingentes. Assim, as metrópoles foram marcadas pela dispersáo espacial e intensificaram o processo de conurbação, incorporando as áreas rurais, expandindo suas manchas urbanas em direção aos municípios limítrofes. Assim, estavam colocados de pé os extensos espaços periféricos metropolitanos. 
QUADRO I | Evoluçáo da populaçáo urbana em relaçáo a populaçáo total - Brasil

\begin{tabular}{|c|c|c|c|}
\hline ANO & $\begin{array}{c}\text { POPULAÇÃo TOTAL } \\
\text { (MILHÓES) }\end{array}$ & $\begin{array}{c}\text { POPULAÇÃO URBANA } \\
\text { (MILHÓES) }\end{array}$ & URBANA/TOTAL (\%) \\
\hline 1940 & 41.236 & 12.876 & 31,2 \\
\hline 1950 & 51.944 & 18.783 & 36,2 \\
\hline 1960 & 70.967 & 31.991 & 45,1 \\
\hline 1970 & 93.139 & 52.085 & 55,9 \\
\hline 1980 & 119.003 & 80.436 & 67,6 \\
\hline 1991 & 146.826 & 110.991 & 75,6 \\
\hline 2000 & 169.873 & 137.925 & 81,2 \\
\hline 2010 & 190.755 & 160.925 & 84,2 \\
\hline
\end{tabular}

FONTE CENSOS DEMOGRÁFICOS, IBGE

Desde a década de 1990, esse intenso crescimento das regióes metropolitanas, se modifica em face de uma nova divisão técnica, social e territorial do trabalho no plano mundial, que resulta em uma refuncionalização das grandes cidades mundiais. Fato que não se diferenciou no Brasil, reforçando o processo de concentração sob outras lógicas (Carlos, 2001).

Trata-se de um processo complexo que redistribui funçóes para as cidades médias, sem desconcentrar das metrópoles o poder de gestão do território. Os dados censitários das décadas de 80 e 90 (demonstrados no quadro 2) demonstram que o processo de metropolizaçáo desacelerou-se em relação aos anos 70 e os dados censitários mais recentes apontam para uma desconcentração da população rumo às cidades metropolitanas.

QUADRO 2 | Crescimento das principais áreas metropolitanas - anual

\begin{tabular}{|c|c|c|c|}
\hline ANO & $\begin{array}{c}\text { POPULAÇÃo TOTAL } \\
\text { (MILHÓES) }\end{array}$ & $\begin{array}{c}\text { POPULAÇÃO URBANA } \\
\text { (MILHÓES) }\end{array}$ & URBANA/TOTAL (\%) \\
\hline 1940 & 41.236 & 12.876 & 31,2 \\
\hline 1950 & 51.944 & 18.783 & 36,2 \\
\hline 1960 & 70.967 & 31.991 & 45,1 \\
\hline 1970 & 93.139 & 52.085 & 55,9 \\
\hline 1980 & 119.003 & 80.436 & 67,6 \\
\hline 1991 & 146.826 & 110.991 & 75,6 \\
\hline 2000 & 169.873 & 137.925 & 81,2 \\
\hline 2010 & 190.755 & 160.925 & 84,2 \\
\hline
\end{tabular}

FONTE CENSOS DEMOGRÁfICOS, IBGE

Observa-se que maior parte das regióes metropolitanas brasileiras deixou de ser polo de intenso crescimento populacional, sobretudo nas duas ultimas décadas. Da média anual de 3,8\% nos anos 70 , o crescimento das regióes metropolitanas 
baixou para uma média de $2 \%$ na década de 80 e para 1,5\% na década de 1990 se mantendo próximo aos mesmos patamares na primeira década do século XXI. Paradoxalmente, algumas novas regióes metropolitanas apresentam números que evidenciam um acelerado processo de crescimento, a exemplo de Goiânia, Manaus, Natal, Maceió, São Luís e Brasília.

O decréscimo do ritmo da tradicional metropolização, concentrada apenas nas nove maiores RM's, se deveu a um conjunto de fatores econômicos e jurídico-institucionais. No âmbito legal, a Constituição Federal de 1988, que no seu artigo 25, delegou aos Estados a prerrogativa de instituir novas Regióes Metropolitanas. O resultado desse instrumento legal no urbano contemporâneo do Brasil é a existência de 22 regióes metropolitanas oficiais, contra 9 dos anos 70; e 26 aglomeraçóes urbanas não metropolitanas, que antes eram a metade, segundo dados do IPEA (2001).

No aspecto econômico a globalização econômica se constituiu em um motor, uma vez que alguns setores produtivos instalados nas aglomeraçóes metropolitanas se desconcentram em direção aos centros de porte médio, localizados nas áreas dinâmicas do país. Essa transferência de atividades produtivas intensificou o crescimento dos municípios mais longínquos, mas também alguns que fazem parte dessas aglomeraçóes metropolitanas, conforme mostra o quadro 3.

QUADRO 3 | Crescimento das principais áreas metropolitanas - municípios nucleares e municípios satélites - 1991/2010

\begin{tabular}{|c|c|c|c|c|c|c|c|c|}
\hline \multirow{2}{*}{$\begin{array}{c}\text { TIPO DE } \\
\text { MUNICÍPIO }\end{array}$} & \multicolumn{3}{|c|}{ POPULAÇÃO } & \multicolumn{3}{|c|}{ DISTRIBUIÇÃo } & \multicolumn{2}{|c|}{ TAXA DE CRESCIMENTO } \\
\hline & I99I & 2000 & 2010 & I99I & 2000 & 2010 & I99I/2000 & $2000 / 2010$ \\
\hline Núcleo & 31.008 & 34.920 & 38.647 & 21,1 & 20,6 & 20,3 & 1,33 & 1,02 \\
\hline Periferia & 20.262 & 26.326 & 30.560 & 13,8 & 15,5 & 16,0 & 2,95 & 1,50 \\
\hline Total & 51.271 & 61.247 & 69.207 & 34,9 & 36,1 & 36,3 & 2,0 & 1,23 \\
\hline
\end{tabular}

FONTE CENSOS DEMOGRÁFICOS, IBGE

Sob o comando delas, há uma (re)hierarquização da rede urbana brasileira, com uma (velha/nova) distribuição de funçóes. Assim, as metrópoles arrefecem seu crescimento e: “(...) deixam de ser sistemas autocentrados para se transformar em potentes entrecruzamentos de redes múltiplas (...)" (Veltz, citado por De Mattos, 2004, p. 165), já seus municípios periféricos passam a atuar como complementares em funçôes secundárias e concentram grandes contingentes populacionais, além de problemas de toda natureza.

Apesar das atividades econômicas se diversificarem e haver abertura de postos de trabalho, esses municípios ainda sofrem a concorrência dos núcleos metropolitanos, que detêm infraestrutura mais elaborada e, portanto, são mais competitivos na atração de investimentos privados dos setores de ponta da economia global.

Assim, se por um lado, alguns municípios metropolitanos encontram novos caminhos no seu processo de desenvolvimento econômico e passam a depender menos dos municípios nucleares, por outro, há um processo que se agrava: a expansão crescente da população e a constituição de uma periferia metropolitana, marcada 
pela ausência de infraestrutura e de acesso aos equipamentos públicos, resultando em baixos indicadores de qualidade de vida e de carência, em todos os níveis. Fato que revela um hiato no entendimento do tecido metropolitano na perspectiva do planejamento e de políticas públicas direcionadas a essas aglomeraçóes, com o tratamento integrado; tema que será objeto de abordagem na próxima seção do artigo.

\section{O planejamento urbano-regional e a questáo metropolitana}

Como já visto a utilização de recortes espaciais para efeito de intervenção do poder público tem sido uma constante em diversas partes do mundo e em diferentes escalas, inclusive a metropolitana. Muitas foram as experiências de planejamento regional em que as delimitaçôes do território serviram de referência para políticas públicas.

Tradicionalmente, na escala macrorregional, no Brasil esses planos se propuseram contemplar setores diversos e, também, atores e agentes com distintos interesses, colocando-os nas arenas das políticas públicas, pelo viés do planejamento implementado pelas Superintendências (Superintendência do Desenvolvimento do Nordeste [sudene], Superintendência de Desenvolvimento do Centro-Oeste [sudeco] e Superintendência do Desenvolvimento da Amazônia [sudam] ${ }^{2}$ nas décadas de 1960 a 1990, quando foram extintas.

No entanto, a escala de planejamento metropolitano só abriu espaço na agenda de políticas públicas quando aprovado o I Plano Nacional de Desenvolvimento (PND), que incorporou os termos "espacial, regional e urbano" trazendo, portanto, um referencial de escala e localização. Por outro lado, o Plano reforçou o modelo das políticas centralizadoras do regime militar, recomendando a criaçáo das Regiōes Metropolitanas, dispositivo que foi atendido prontamente. ${ }^{3}$

Já o II PND priorizou os centros urbanos de porte médio, relegando a um plano secundário as políticas públicas metropolitanas. Isso decorreu de uma decisão paradoxal que partiu da seguinte premissa: as metrópoles são espaços privilegiados pelas escolhas do capital e, portanto, possuem instrumentos de autogestão, sobretudo financeiros. Assim, ao deixar as regióes metropolitanas por conta das forças de mercado, o poder público reforçou o movimento de atração populacional e, consequentemente viu aumentarem os problemas, revelando um circulo de expansão do tecido urbano com deficiências na infraestrutura urbana e concorrência no acesso a bens e serviços coletivos.

Outro paradoxo se situa na dimensão espacial, considerando que a escala regional e metropolitana que se fez presente nos Planos Nacionais sucumbia a um viés setorial que passou a pautar as iniciativas do governo central. Neste sentido Gouvêa (2005) aponta:

A dinâmica de crescimento das cidades, quase sempre foi desordenado e até mesmo caótico, foi demonstrando gradativamente a ineficiência dos inúmeros programas e projetos implementados em módulos isolados e desenvolvidos a partir da ideia

2 Foram recriadas pelas Leis Complementares nº 124,125 e 129.

3 A Lei Complementar $n^{\circ} 14$, de 1973, criou as RM's de Belém, Fortaleza, Recife, Salvador, Belo Horizonte, Porto Alegre, Curitiba e São Paulo. 
equivocada de que a realidade urbana poderia ser dividida e tratada de maneira compartimentada e estanque, sem gerar maiores implicaçóes sobre o sistema como um todo. (p. 33)

$\mathrm{Na}$ década de 1990, as políticas de desenvolvimento regional sucumbem definitivamente a essa conotaçáo setorial, marcando um cenário que aponta para o fim do planejamento de cunho regional e procura oferecer diferentes usos do território de acordo com agentes e atores distintos. Isso reforçou a fragmentaçáo dos projetos regionais, alimentando um discurso de "competitividade espacial", que resultou na exclusão de determinados lugares e setores produtivos. Isso levou a um quadro de competição entre os estados brasileiros, a denominada Guerra Fiscal, quando o poder público atua oferecendo renuncias e incentivos para atrair investimentos privados.

$\mathrm{Na}$ escala metropolitana tal processo se manifestou sob a forma de uma redistribuição de funçôes e reconversão econômica de alguns municípios, que redimensionam seus papeis. $\mathrm{O}$ que se observa, portanto, é uma redefiniçãa da divisão territorial, intra-metropolitana, do trabalho, que alimentou os fluxos migratórios para essas áreas periferias e que náo foi acompanhada pela adequada dotação de infraestrutura nem tampouco oferta de bens e serviços públicos.

Assim, políticas de planejamento, nas diversas escalas, são substituídas por planos setoriais e instrumentos de competição nas escalas locais. No caso do Brasil, existem marcas temporais claras desse processo, quando em meados da década de 1980 os tradicionais órgáos de planejamento e desenvolvimento regional, entre os quais se destacavam a SUDENE e a SUDAM, entram em colapso e nos anos subsequentes se enfraquecem substancialmente, sendo extintas por Medida Provisória em 2001.

Se do ponto de vista da intervenção dos espaços maiores há uma desestruturação, na escala metropolitana, essa perda de rumo, tomou ares quase desastrosos. Isso porque, as referencias de planejamento ou eram macro regionais ou entáo locais. Assim, apesar da vida econômica, política, social e cultural do país girar em torno das metrópoles a escala metropolitana tornou-se uma ilustre desconhecida dos processos de planejamento territorial e da agenda de políticas públicas.

A ausência de regulação dos espaços urbanos jogou as cidades, de forma geral, no limbo do ordenamento dos seus territórios, fato que se agravou nas metrópoles, visto que nelas esse mosaico espacial e complexo, demanda respostas, via políticas públicas, de curto, médio e longo prazos, as quais parecem estar sempre "atrasadas" em face da velocidade das transformaçóes ocorridas ali.

Abandonada por alguns anos a política urbana foi retomada com a institucionalização da temática, através do Ministério das Cidades, que tem priorizado as grandes áreas urbanas do país, enfatizando os grandes déficits encontrados nas regióes metropolitanas, desde habitaçáo, ao saneamento, passando pela mobilidade urbana. No entanto, o arranjo espacial ainda guarda o município como espaço privilegiado de intervenção pública, havendo uma clara dificuldade no enfrentamento dos problemas tendo por base a escala metropolitana. Neste sentido Gouvêa (2005) afirma:

O fato de não constituírem um nível de governo institucionalizado na estrutura político-administrativa do país torna difícil o equacionamento das relaçóes de poder para efeito de formulação e implementação de políticas públicas estratégicas e abrangentes. (p. 18) 
Dessa forma, ao se constituírem com repositórios de uma serie de processos complexos, as RM's, se deparam com a dificuldade em dialogar com as demais políticas setoriais, considerando esses recortes múltiplos das diferentes instituiçóes, que nem sempre priorizam ou se mostram sensíveis aos problemas metropolitanos.

Portanto, os efeitos das intervençóes poderão se manifestar com intensidade variada nesses espaços urbanos. Essa perspectiva setorial das políticas públicas impóe as RM's um reordenamento territorial, constante, que busca a conectividade com os interesses da iniciativa privada, sobretudo da reprodução do capital imobiliário. Sob tal aspecto a contribuição de Sposito (2001) é de grande importância:

... no nível intra-urbano, o poder público escolhe, para seus investimentos em bens e serviços coletivos, exatamente os lugares da cidade onde estão os segmentos populacionais de maior poder aquisitivo; ou que poderão ser vendidos e ocupados por esses segmentos, pois é preciso valorizar as áreas. (p. 74)

Ao oferecer usos diferenciados dos espaços urbanos essas políticas públicas garantem a reprodução do capital privado e, portanto, perpetuam as desigualdades intrametropolitanas, valorizando determinadas fraçôes do tecido urbano, inclusive com o forte adensamento de infraestrutura e serviços públicos.

Logo, a viabilidade de alguns setores da economia urbana tem o poder público como indutor, que constrói infraestrutura e, a partir dessa dotação, a iniciativa privada atua, em um ciclo que gera valorização fundiária, processo do qual se beneficiam, tanto o Estado como os produtores privados dos espaços. Neste sentido Abramo corrobora com a afirmação de Sposito, ao comentar que: “(...) as empresas tomam suas decisóes de localização respeitando o principio da maximização de seus lucros" (Abramo, 2001, p. 69). Portanto, para algumas atividades econômicas as escolhas espaciais se dão em função de um conjunto de aspectos que vão influenciar diretamente na sua reprodução. Essas escolhas vão resultar em áreas mais desenvolvidas e outras com menor grau de desenvolvimento, formando um mosaico de espaços bastante heterogêneo, manifestados inclusive na escala metropolitana.

No Brasil, os desequilíbrios regionais são resultantes de processos históricos e com dinâmicas de intensidade diversas revelando um cenário de pauperização, que vai da esfera individual ao coletivo, ou seja, se expressa nos territórios. Assim, o problema passa a ter relevância, ligando-se, diretamente, à formulação de políticas de planejamento regional, que têm sido, também, no caso do Brasil, uma luta pelo desenvolvimento e contra pobreza dos indivíduos e da ausência de dinâmica econômica das regióes.

Em face das evidentes desigualdades espaciais, a questão regional tem sido uma preocupação para o desenvolvimento do país, cabendo a União a redução desses desequilíbrios nas diversas escalas, conforme dispóe a Constituição Federal de 1988.

No entanto, a amplitude do conceito de desenvolvimento ${ }^{4}$ e a pluralidade de critérios para qualificar regióes desenvolvidas e regiōes deprimidas, revelam um cenário que ora aproxima essas políticas, tornando-as mais eficazes, em outros 
momentos elas se tornam assimétricas resultando em frustraçóes para a arena de atores envolvidos e, consequentemente, para as regióes.

É nesse sentido que a próxima seção do artigo pretende encaminhar a discussão entre esse caminho que por vezes é tangencial e por vezes simétrico no diálogo entre a PNDR e os espaços metropolitanos do país.

\section{Municípios metropolitanos: uma lacuna espacial da PNDR}

Embora expresse de forma explícita que seu objeto não é a pobreza, dispersa ou concentrada, como aquela encontrada nas grandes cidades, a PNDR tem foco na diminuiçẫo das desigualdades regionais, em diversas escalas, uma vez que a construção de sua tipologia relativiza, através de indicadores, as diferenciaçôes espaciais.

A PNDR enquanto política que pretende ser referência para açóes convergentes de outras políticas setoriais e, para tanto adota um recorte espacial particularizado seguindo a classificação apresentada no Mapa 1 que apresenta sua tipologia com vistas a orientar seus instrumentos.

\section{Mapa I | Tipologia da Política Nacional de Desenvolvimento Regional}

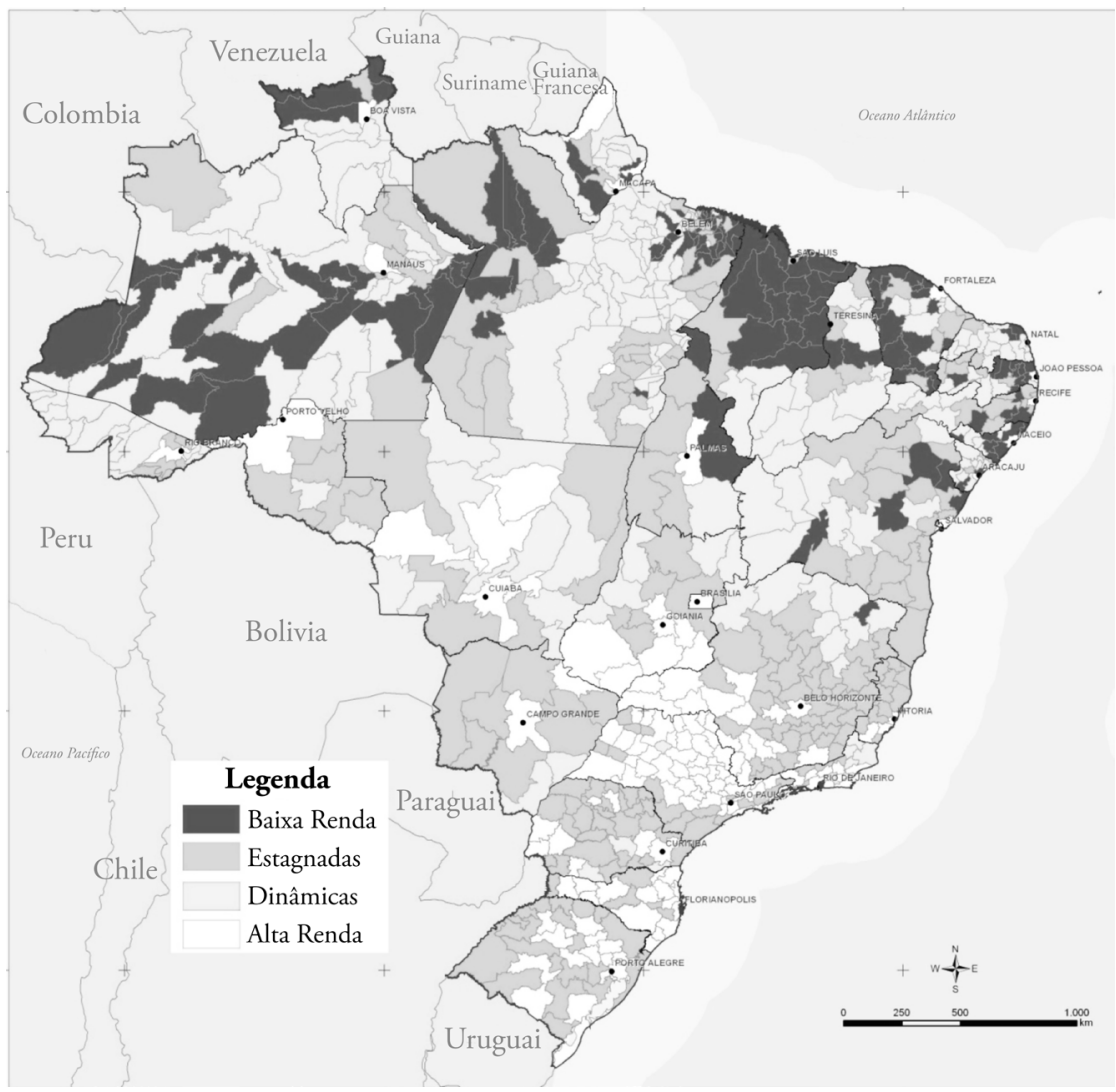

FONTE SÍTIO ELETRÔNICO DO MINISTÉRIO DA INTEGRAÇÃO NACIONAL, ACESSADO EM OI/IO/2OI 5 
Por um lado, a agregação dos dados que permitiram a classificação e a tipologia da política resulta em um avanço, pois já distinguem e demonstram as desigualdades, por outro lado, reforçam tratamentos injustos com aqueles municípios pertencentes às RM's brasileiras, que ficam à margem desses instrumentos de desenvolvimento.

Logo, as referências espaciais não se expressam nas demais políticas setoriais do governo e em alguns momentos podem divergir completamente, dadas a conjuntura e as escolhas feitas pelos atores que atuam nessas arenas.

Assim, ao classificar algumas dessas MRG's em alta renda e explicitar que tais regiôes não são objeto da PNDR, a política corre o risco de deixar de fora do seu conjunto de instrumentos aqueles municípios, que se tomados isoladamente, estariam em outra categoria. Tal fato pode resultar em um cenário futuro de aprofundamento das desigualdades no âmbito do espaço metropolitano uma vez que a classificação da alta renda está associada, sobretudo as maiores cidades do país.

Quando a PNDR se coloca como referência espacial para ação de outras instituiçóes e classifica alguns desses municípios como alta renda, pode reforçar um aprofundamento nas desigualdades intra-metropolitanas. Em face dessa categorização há uma probabilidade grande desses municípios serem alijados das políticas publicas e, consequentemente, de investimentos, exatamente nas áreas que mais necessitam de serviços públicos para os contingentes populacionais, quase sempre marcados pela pobreza, bem como açóes voltadas para a sua dinamização produtiva.

A seguir pretende-se demonstrar por alguns dados relativos a diferentes RM's, como a discussão anterior pode ter reflexos, observe-se as informaçóes relativas a MRG de Salvador no que diz respeito ao PIB per capita, como se observa no quadro 4:

QUADRO 4 | PIB per capita dos municípios da MRg de Salvador

\begin{tabular}{|l|c|c|c|}
\hline \multicolumn{1}{|c|}{ MUNICÍ́PIO } & I99I & 2000 & 20I0 \\
\hline Camaçari & 258 & 334 & 462 \\
\hline Candeias & 249 & 300 & 460 \\
\hline Dias D'ávila & 274 & 305 & 476 \\
\hline Itaparica & 138 & 257 & 1.031 \\
\hline Lauro de Freitas & 437 & 651 & 517 \\
\hline Madre de Deus & 231 & 332 & 451 \\
\hline Mata de São João & 185 & 261 & 443 \\
\hline Pojuca & 249 & 281 & 973 \\
\hline Salvador & 570 & 685 & 433 \\
\hline São Francisco do Conde & 204 & 248 & 411 \\
\hline São Sebastiáo do Passé & 213 & 249 & 431 \\
\hline Simónes Filho & 234 & 304 & 408 \\
\hline Vera Cruz & 198 & 292 & \\
\hline
\end{tabular}

FONTE ATLAS DO DESENVOLVIMENTO HUMANO, 2015 
Alguns números evidenciam a persistência dessas assimetrias, a exemplo da Regiáo Metropolitana de Salvador, onde o município núcleo possui um PIB per capta 4,1 vezes superior a municipalidade que se encontra no limite inferior, o que revela de início a expressividade da economia soteropolitana em detrimento do restante, já que ali se concentra o maior produto interno bruto, bem como de um contingente populacional bem superior ao restante dos demais municípios.

Essas desigualdades que já existem, podem se intensificar, levando esses municípios das MRG's metropolitanas ao agravamento de um quadro marcado pelo crescimento desordenado, visto que são esses municípios que recebem maior parte dos contingentes migratórios, e os Censos recentes mostram isso. Logo, são áreas de acelerado crescimento populacional, marcadas pela pouca densidade de bens e serviços, que geralmente, mantém uma vida de relação intensa com os municípios nucleares, onde se concentra a maior parte da oferta de postos de trabalho. Isso resulta em um tecido urbano metropolitano marcado pela informalidade e espontaneidade, sem a devida dotação de infraestrutura nessas áreas periféricas.

Mesmo em regiôes metropolitanas mais dinâmicas os municípios da periferia continuam distantes na produção da riqueza, concentrando os setores mais nobres da economia, como mostram os casos de Porto Alegre, com PIB da ordem de R \$ 43,0 bilhôes e Canoas que é o segundo Produto Interno da regiáo metropolitana chegando a R \$ 16,5 bilhóes; ou mesmo Curitiba com seus R \$ 53,1 bilhôes e São Jose dos Pinhais com $\mathrm{R} \$ 13,6$, aquele que mais se aproxima da capital paranaense (Censo, 2010).

Outro bom exemplo das assimetrias internas e da desconexão entre as políticas é dado pela sequência de municípios integrantes MRG de Belém que possuem água encanada e banheiros, conforme se verifica no quadro 5 .

QUADRo 5 Percentuais de domicílios com banheiro e água encanada da MRG de Belém, por municípios

\begin{tabular}{|l|c|c|c|}
\hline \multicolumn{1}{|c|}{ MUNICírIO } & I99I & 2000 & 20IO \\
\hline Ananindeua & 53 & 68 & 92 \\
\hline Belém & 75 & 80 & 96 \\
\hline Benevides & 44 & 52 & 92 \\
\hline Castanhal & 51 & 57 & 89 \\
\hline Marituba & 22 & 39 & 92 \\
\hline Santa Barbara & 37 & 44 & 90 \\
\hline Santa Isabel & 30 & 52 & \\
\hline
\end{tabular}

FONTE ATLAS DO DESENVOLVIMENTO HUMANO, 20 I 5

O quadro anterior é um exemplo da diferenciação existente na dotação de infraestrutura e serviços públicos no interior das regióes metropolitanas. $\mathrm{O}$ município nuclear, Belém, embora apresente baixo percentual de domicílios servidos de água encanada e banheiros, encontra-se em patamar superior a todos os demais 
que integram a MRG, apresentando, no ano de 1990, quase o triplo daquele que se encontra no intervalo inferior.

A evolução dos indicadores, que no ano de 2010 colocaram quase todos os municípios da MRG Belém em patamares semelhantes, se deveu muito mais a política de saneamento, do que propriamente a açóes voltadas para o desenvolvimento da regiáo na perspectiva mais sistêmica. Assim, os investimentos mesmo quando apresentam bons resultados não decorrem de uma ação coordenada para incluir os indivíduos e não se dão dentro de uma estratégia de tornar essas áreas urbanas competitivas nem atrativas para os investimentos.

Outro bom estudo seria aquele relacionado às necessidades, relacionadas ao transporte público, da população da MRG de Belo Horizonte, constatadas no quadro 6 .

QUADRo 6 | Deslocamento para estudo e trabalho na MRG de Belo Horizonte

\begin{tabular}{|l|c|c|}
\cline { 2 - 3 } \multicolumn{1}{c|}{} & $\begin{array}{c}\text { QUANTIDADE DE PESSOAS QUE } \\
\text { TRABALHAM OU ESTUDAM }\end{array}$ & $\begin{array}{c}\text { PESSOAS QUE SE DESLOCAM PARA FORA } \\
(\%) \text { DO MUNICÍPIO DE DOMICÍLIO }\end{array}$ \\
\hline Belo Horizonte & 1.147 .857 & 49.676 \\
\hline Demais municípios & 941.460 & 248.340 \\
\hline
\end{tabular}

FONTE COMO ANDA BELO HORIZONTE, 2008

Se o processo de formação das metrópoles brasileiras reforça a primazia dos municípios nucleares em detrimento dos demais, seja pela concentração de infraestrutura, de serviços e da maior oferta de postos de trabalho, é "natural" que essa relação demande grande volume de deslocamentos intraurbanos, as denominadas migraçóes pendulares.

Esses fluxos, historicamente, representam um dos principais dilemas das regióes metropolitanas, gerando no primeiro momento uma forte concentração nas áreas centrais para depois se deparar com um vasto leque de problemas que resultam, inclusive, em "deseconomias". Portanto, o enfrentamento da questão via de políticas relacionadas ao transporte urbano deve ser um ponto de constante preocupaçáo.

No caso da RM de Belo Horizonte, o quadro 4 mostra o numero de pessoas que dependem de alguma forma do município central, seja para trabalhar, seja para ter acesso a bens e serviços. Logo, o sistema de transporte, em suas múltiplas modalidades, se vê fortemente pressionado. No caso específico, os números não são capazes de demonstrar o número de pessoas que utilizam cada modal, mas podem apontar para um alto percentual de pessoas, que são obrigadas a se deslocar corroborando com os congestionamentos e superlotação dos sistemas de massa.

Assim, o acelerado crescimento desses municípios periféricos, que carecem de investimentos na área de transporte coletivo, principalmente os sistemas de trens metropolitanos e a abertura de corredores viários, de utilizaçáo seletiva. Investimentos de grande monta, uma vez que não são contabilizados apenas os equipamentos, mas todo um conjunto de custos da desapropriaçáo (com pagamento de indenizaçôes) de vastas áreas até a manutenção desses sistemas por toda vida. 
As metrópoles brasileiras têm se debatido em torno do transporte público e do esgotamento desses sistemas frente às crescentes demandas das populaçóes. Trata-se de uma questão tão delicada que a temática deixa de ter a abordagem macro, no âmbito do Ministério dos Transportes, para se incorporar a agenda das políticas urbanas, com uma secretaria específica no Ministério das Cidades, com competências definidas para atuar no âmbito das médias e grandes cidades brasileiras nas questôes relacionadas à temática.

Há ainda que se considerar como parte dessa estratégia, por diminuir a pressão por bens e serviços nos municípios nucleares, a Lei $\mathrm{n}^{\circ} 10.257 / 01$ e mais recentemente a Lei $\mathrm{n}^{\circ} 13.089 / 15$ que disciplina o planejamento municipal e metropolitano, respectivamente. A primeira orienta inclusive o ordenamento urbano, o seu polinucleamento; descomprimindo, assim, essas áreas centrais e permitindo uma dinamização econômica das áreas adjacentes.

Ao redirecionar os fluxos em função desse polinucleamento, os sistemas de transportes metropolitanos certamente serão menos demandados nesses extensos deslocamentos diários e o gap existente hoje entre a oferta e a demanda, também pode diminuir.

Quando tomamos por base rendimentos per capita, áreas tradicionalmente vistas como "prósperas" a exemplo da cidade de Curitiba, classificada como alta renda pela PNDR, é possível a revelação de dados conflitantes, desmistificando esse entendimento construído no imaginário coletivo da população brasileira, observados no quadro 7.

QUADRo 7 | Média de rendimentos, MRG de Curitiba, por municípios

\begin{tabular}{|l|c|c|c|}
\hline \multicolumn{1}{|c|}{ MUNICÍPIO } & I99I & 2000 & 20I0 \\
\hline Adrianópolis & 214 & 228 & 519 \\
\hline Agudos do Sul & 220 & 303 & 646 \\
\hline Almirante Tamandaré & 295 & 401 & 814 \\
\hline Araucária & 371 & 488 & 652 \\
\hline Balsa Nova & 283 & 401 & 547 \\
\hline Bocaiúva do Sul & 242 & 374 & 671 \\
\hline Campina Grande do Sul & 343 & 426 & 488 \\
\hline Campo do Tenente & 188 & 284 & 749 \\
\hline Campo Largo & 368 & 530 & 567 \\
\hline Campo Magro & 329 & 449 & 342 \\
\hline Cerro Azul & 160 & 245 & 682 \\
\hline Colombo & 349 & 476 & 612 \\
\hline Contenda & 309 & 411 & 1581 \\
\hline Curitiba & 878 & 1225 & 277 \\
\hline Doutor Ulysses & 119 & 395 & 677 \\
\hline Fazenda Rio Grande & 338 & & \\
\hline
\end{tabular}


(continuaçâo)

\begin{tabular}{|l|c|c|c|}
\hline \multicolumn{1}{|c|}{ MUNICÍPIO } & I99I & 2000 & 20I0 \\
\hline Itaperuçu & 184 & 268 & 468 \\
\hline Lapa & 282 & 471 & 608 \\
\hline Mandirituba & 255 & 457 & 539 \\
\hline Piên & 232 & 444 & 541 \\
\hline Pinhais & 425 & 589 & 911 \\
\hline Piraquara & 384 & 425 & 581 \\
\hline Quatro Barras & 419 & 630 & 800 \\
\hline Quitandinha & 182 & 324 & 452 \\
\hline Rio Branco do Sul & 247 & 349 & 548 \\
\hline Rio Negro & 390 & 527 & 709 \\
\hline Sáo José dos Pinhais & 452 & 619 & 846 \\
\hline Tijucas do Sul & 223 & 333 & 547 \\
\hline Tunas do Paraná & 175 & 344 & 431 \\
\hline
\end{tabular}

FONTE ATLAS DO DESENVOLVIMENTO HUMANO, 2015

O município nuclear se distancia de todos os demais e a média de seus rendimentos chega a ser 7,4 vezes maior que a do município que se encontra no limite inferior, observe-se que, passados vinte anos (1991-2010) essa proporção se mantém em 5,7 vezes. Em relação ao segundo município com maior média entre 1991 e 2000 a proporção se manteve em torno de 1,9, caindo no ano de 2010 para 1,75.

Ressalte-se que os investimentos privados são os principais motores do crescimento em alguns municípios, principalmente pela instalação de grandes montadoras automobilísticas transnacionais, bem como da presença do aeroporto Afonso Pena e das atividades que lhes são complementares, caracterizando essas áreas com um cluster de logística.

Os municípios com as piores médias, pois são caracterizados por postos de baixa remuneração e, de forma geral, concentram uma força de trabalho pouco qualificada. Tal fato gera pouca circulação monetária, uma vez que a reprodução dos indivíduos se dá no limite de suas necessidades (habitação, alimentação e transporte) sobrando pouco para outros gastos. São, portanto, marcadas pela insipiência de suas atividades econômicas e caracterizadas como cidades-dormitórios.

Dessa forma, há uma alta dependência dos empregos ofertados e, consequentemente, de salários provenientes do município núcleo, onde esses trabalhadores passam maior parte do dia e onde realizarão aqueles gastos supérfluos (quando podem), retroalimentando um círculo de baixa dinâmica econômica das suas cidades de residência em face da ausência de atividades mais elaboradas.

Essa breve analise pretendeu fazer uma varredura espacial para demonstrar a persistência das desigualdades, pois foram analisados exemplos de algumas das mais importantes metrópoles brasileiras e assim demonstrar a necessidade de políticas complementares que tomem as RM's como recorte prioritário e dialoguem com a escala regional para promover o desenvolvimento mais equilibrado dos seus municípios. 
Aqui ainda nos propomos a uma última discussão que evidencia uma relação paradoxal entre duas políticas que se conectam umbilicalmente: a escala das questôes metropolitanas é similar a da política regional, pois se estabelece em cima de um conjunto de municípios em limites mais extensos que são partem das relaçóes existentes para agrupar entre essas municipalidades.

\section{Os avanços no dialogo das escalas}

Esse distanciamento já fora apontado em um processo de avaliação da PNDR, realizado em, quando o Relatório sinaliza com algumas questóes:

O ponto central na PNDR é institucionalização. Como você institucionaliza? Como coordena as várias escalas de desenvolvimento? Como integra a essa política regional as experiências do Território da Cidadania e dos APLs? E, ao mesmo tempo, como é que você integra essas superintendências macrorregionais que ainda podem ser o 'cimento' de uma coisa mais efetiva no futuro? (Brasil, 2011, p. 21)

Apesar da menção a duas políticas de dimensão territorial, é sabido que essa característica se relaciona a um conjunto muito mais amplo de iniciativas governamentais que estabelecem pouco dialogo entre si, principalmente na questão das suas escalas.

Assim, além dessa critica e de outras a PNDR se reconhecia a necessidade de reformular a PNDR, revendo um conjunto de estratégias e instrumentos que estavam presente no Decreto $n^{\circ} 6047$. Nesse sentido o Ministério da Integração Nacional realizou um amplo processo conferencial para discutir com a sociedade civil organizada quais seriam as melhorias necessárias a política regional brasileira.

O resultado dessa participação foi a elaboração do Anteprojeto de Lei que institui a PNDR - Fase II, já em fase de tramitação no Congresso Nacional ${ }^{5}$, que amplia seus objetivos e reconhece diversas escalas e seus arranjos institucionais, incluindo-se ai as regióes metropolitanas e os consórcios públicos. $\mathrm{O}$ caminho a ser percorrido pela proposição pode ser rápido ou ainda muito longo, a exemplo de outros marcos legais que ultrapassaram uma década na sua tramitação. Assim, no atual momento não existe aproximação da política regional brasileira com a dimensão municipal, ou mesmo metropolitana.

De outro lado, pode-se mencionar a publicação, em 12 de janeiro de 2015, da Lei $\mathrm{n}^{\circ} 13.089$, conhecida também como Estatuto da Metrópole que disciplina o funcionamento das regióes metropolitanas no país. Ressalte-se que, ao tratar do planejamento de regióes metropolitanas e aglomeraçóes urbanas a legislaçáo resgata a escala as microrregióes, quando associadas a esses arranjos de múltiplas cidades, ultrapassando assim o limite municipal, reconhecendo esses organismos como um conjunto que se integra e possui dinâmicas econômicas e serviços complementares, além de problemas comuns.

A legislação prevê a elaboração do Plano de Desenvolvimento Urbano Integrado que deve obedecer ao recorte da RM ou das aglomeraçóes e, portanto, se constitui em um instrumento de escala regional dialogando assim com a PNDR, fazendo

O Projeto de Lei $n^{\circ} 375$ foi apresentado no dia 17 de junho de 2015 pelo Senador Fernando Bezerra. 
menção a esse recorte que aí é entendido como supramunicipal e pode ser uma escala importante, principalmente para as maiores aglomeraçóes urbanas do Brasil.

Apesar dos avanços trazidos pelo Estatuto da Metrópole ainda persistem alguns problemas de escala, que reclamam um maior diálogo com uma política de escala regional, tais como:

- A manutenção de RM já instituídas por leis complementares estaduais. O caso de Santa Catarina no Brasil é emblemático que tornou todo seu território, ${ }^{6}$ que na realidade não apresentam as características da Lei $\mathrm{n}^{\circ} 13.089$ e, portanto, não se constituem como áreas de integração econômica, nem de complementaridade de políticas públicas e/ou serviços. A saída foi torná-las aglomeraçôes urbanas, segundo dispóe a própria lei, sem, no entanto, enfrentar aspectos fundamentais que ultrapassam somente o aspecto conceitual e recaem sobre a natureza das relaçôes existentes entre os municípios. Assim, a intensidade desses fluxos e da vida de relação é um fator determinante para se constituir uma região metropolitana ou aglomerado urbano, apesar de se saber da complexidade existente nessas áreas e que a complementaridade nem sempre se dá baseada em uma lógica de proximidade.

- O problema da formação de regióes metropolitanas ou aglomeraçóes que possuem municípios de distintas unidades da federação está disciplinado pela Lei, desde que aprovada pelas casas legislativas estaduais. No entanto, a falta de regulamentação pode levar, ao menos no presente momento, a problemas de ordem econômica em face de algumas unidades da federação apresentarem uma longa trajetória de políticas de incentivo e atração de investimentos privados, muitas vezes predatórias, ou seja, corre-se o risco de se instituir uma guerra fiscal, de âmbito municipal. Essa possibilidade é verdadeira e muito provável, considerando que o artigo $5^{\circ}$ da Lei não estabelece questóes dessa ordem como fundamentais. ${ }^{7}$ Dessa forma, ao invés de corroborar para a política regional, que em geral se pauta por solidariedade, o hiato legal, pode se mostrar controverso.

- A questão da governança é outro aspecto a se refletir. No cenário de assimetrias que marca a federação brasileira e as regióes metropolitanas onde, em geral, o município nuclear é o detentor de maior poder político, técnico e institucional, os dispositivos da lei que garantem compartilhamento de responsabilidades, prevalência de interesse comum sobre o local e observância das peculiaridades locais, pode não ser mais do que um enunciado de boas intençôes, considerando

6 Região Metropolitana Carbonífera; Região Metropolitana de Chapecó; Região Metropolitana do Contestado; Região Metropolitana do Extremo Oeste; Regiāo Metropolitana de Florianópolis; Região Metropolitana da Foz do Rio Itajaí; Região Metropolitana de Lages; Região Metropolitana do Norte/Nordeste Catarinense; Regiâo Metropolitana de Tubarão; Região Metropolitana do Vale do Rio Itajaí Regiāo Metropolitana do Vale do Rio Itajaí.

7 Art. 5o As leis complementares estaduais referidas nos arts. 3o e 40 desta Lei definirão, no mínimo: I - os Municípios que integram a unidade territorial urbana; II - os campos funcionais ou funçôes públicas de interesse comum que justificam a instituição da unidade territorial urbana; III - a conformação da estrutura de governança interfederativa, incluindo a organização administrativa e o sistema integrado de alocação de recursos e de prestação de contas; e IV - os meios de controle social da organização, do planejamento e da execução de funçóes públicas de interesse comum. 
que na ausência de uma política de escala regional, a distribuição dos serviços e das benfeitorias que atraiam investimentos pode ser feita de forma desequilibrada. Assim, uma política com perspectiva regional que vá para além dos limites da região metropolitana ou do aglomerado urbano poderia favorecer esses municípios periféricos e fortalecer seu papel no processo de desenvolvimento em escala mais ampla.

- No que se refere aos instrumentos de gestáo. Apesar do Plano de Desenvolvimento Integrado Urbano existe uma probabilidade de que tais instrumentos se desconectem das políticas federais que se dão, preferencialmente, na escala municipal e assim reforcem desigualdades no âmbito intrametropolitano, considerando que a operação desses instrumentos passa pela capacidade diferenciada de formulação, implementação e avaliação das iniciativas do governo central.

- A ausência de um instrumento de financiamento para fomentar esse processo de desenvolvimento é outra lacuna deixada pela Lei, considerando que o Fundo Nacional de Desenvolvimento Urbano Integrado, foi vetado na integra. Assim, se mantém um cenário de concorrência, muitas vezes predatória, por recursos para políticas públicas estruturantes, uma vez que maior parte das políticas públicas, através de transferências voluntárias, opera por convênios com municípios. Dessa forma, a política regional que considera na essência uma escala supramunicipal pode ser a saída para o financiamento dessas açóes. ${ }^{8}$

Assim, apesar dos avanços trazidos pela legislação que institui o planejamento integrado para as regióes metropolitanas e aglomerados urbanos brasileiros os elos com a escala regional ainda precisam ser reforçado pelo aperfeiçoamento das políticas públicas que tratam de ambos os temas.

Se por um lado, a Política Nacional de Desenvolvimento Regional reconhece que as desigualdades se expressam em diferentes escalas, inclusive na intra-urbana, náo faz sentido ela náo considerar a escala metropolitana, pois esta se encontra em um patamar superior ao da cidade isoladamente.

Isso fica patente em face dos problemas que atualmente acometem as metrópoles brasileiras, sobretudo naquilo que diz respeito aos serviços públicos e acesso a bens coletivos, aspectos que uma política de desenvolvimento regional não conseguiria solucionar isoladamente e nem tem mandato legal, no caso do Brasil.

As consideraçóes que seguem são mais do que o encerramento, provisório, do debate e pretendem encaminhar questóes que indiquem possibilidades para uma Política Metropolitana que dialogue com a PNDR, de forma continuada.

\section{Consideraçóes finais}

Desde a promulgação da CF de 1988, foram transferidas aos estados as competências para criação das RM's. No entanto, somente criá-las e aguardar pela atuação isolada das políticas setoriais que tenham esses espaços como prioridade não é o bastante. Há que se criar as institucionalidades que planejem esses espaços distribuindo os

O Anteprojeto de Lei prevê a instituiçấo de um Fundo Nacional para o Desenvolvimento Regional, voltado para o financiamento do setor público. 
ativos e oportunidades e que coordenem as políticas setoriais dando-lhes um caráter metropolitano, entendidas no sentido amplo e efetivo.

O momento vivido pelo país, que instituiu a PNDR e o Estatuto da Metrópole, abre as portas para o estabelecimento de instâncias participativas nos processos de formulação, implementação e avaliação de políticas públicas. Logo, a criação de organismos de planejamento em escala metropolitana pode se constituir em uma interessante arena de debates e embates que resulte na otimização de recursos e em uma distribuição mais justa dos bens e serviços para as populaçóes das cidades periféricas.

Embora tenham grande importância na vida econômica, social e cultural do país as RM's não possuem um espaço oficial, em forma de colegiado (como já existe para outros recortes espaciais) para que haja um debate com os órgãos setoriais e abrir canais para interlocução, replicando experiências bem sucedidas e avaliando os ajustes naquelas que não tiveram sucesso. Isso náo é solucionado em face da existência do Conselho das Cidades, considerando que a lógica dessas áreas se distingue completamente dos municípios de porte médio e pequeno, os quais são a maioria no país. A agenda metropolitana é urgente e lida com passivos de enorme magnitude, carecendo de um espaço exclusivo para tratar de seus problemas.

Cabe ressaltar que tais instituiçốes não lograrão êxito se não houver um marco regulatório para o seu funcionamento bem como, um espaço na distribuição dos recursos orçamentários das três instancias de poder, bem como de um maior fortalecimento técnico e institucional para combater as assimetrias que ainda persistem na federação brasileira e se reproduzem na escala metropolitana, favorecendo determinadas municipalidades em detrimento de outras.

O caminho já esta aberto com alguns instrumentos legais existentes, como o a Lei $n^{\circ} 10.257 / 01$ e a Lei $n^{\circ} 13.089 / 15$; há necessidade, no entanto de regulamentações específicas e complementares no âmbito dos estados e de municípios, reforçando o recorte espacial metropolitano, não no sentido de alimentar esse crescimento de forma inconsequente, mas de forma a otimizar os investimentos, tanto público como privados em benefício da regiâo metropolitana como um todo.

Portanto, cabe ao executivo a partir de suas experiências, propor instrumentos legais às casas legislativas e conclamar a participação popular na aprovação, urgente desse marco. Ademais, cabe ao executivo o esforço por garantir os recursos destinados a essa Política Metropolitana, bem como possibilitar diálogos entre as diferentes ações, de forma a evitar desperdícios e superposição.

Esse diálogo, passa pelo reconhecimento dos diferentes recortes espaciais e da forma que esses recortes se entrecruzam nas RM's. Há, portanto que se compreender os dinâmicos e complexos processos que rebatem nessas áreas e estar sensível às consequentes redefiniçôes que se farão necessárias nas políticas públicas e no enfrentamento diário de problemas de toda ordem.

Esse pode também, ser o passo inicial para uma mudança cultural de redirecionamento dos fluxos econômicos e migratórios, que ainda persistem com a ideia (não de todo equivocada) que as melhores "oportunidades" se localizarem nas RM's. Ao estabelecer uma nova centralidade urbana, se desacelera esse ritmo de crescimento das metrópoles, tendendo ao arrefecimento das desigualdades e, se, acompanhada 
de um planejamento, confere-se prioridade aquelas cidades que podem se constituir em futuros polos de desenvolvimento nas suas regióes. Trata-se, de uma redefinição territorial do trabalho, que procura romper o estado de coisas existente e diminuir as iniquidades encontradas no território brasileiro.

Não há, portanto, que se pensar em um modelo linear na formulação dessas políticas públicas nem, do conjunto de ações intentadas por elas. Essa forma de conduzir os nexos entre a PNDR e uma Política Metropolitana pode ser o caminho, inclusive para repensar esse modelo concentrador, que levou ao esgotamento as maiores cidades do país, bem como refletir em que medida as RM's podem contribuir com as cidades de porte médio no sentido de redesenhar a rede urbana brasileira distribuindo/compartilhando esse "poder", equilibrando os espaços regionais indo, portanto, ao encontro do que deseja a PNDR.

\section{Referências bibliográficas}

Abramo, P. (2001). Mercado e ordem urbana. Rio de Janeiro: Bertrand Brasil.

Brasil. (1973). Lei Complementar $\mathrm{n}^{\circ}$ 14, de 1973. Dispóe sobre a criaçáa das regióes metropolitanas de Belém, Belo Horizonte, Curitiba, Fortaleza, Porto Alegre, Recife, Salvador e São Paulo. Diário Oficial, Brasília.

Brasil. (2001). Lei $\mathrm{n}^{\circ}$ 10.257, de 10 de julho de 2001. Estabelece diretrizes gerais da política urbana. Diário Oficial, Brasília.

Brasil. (2005). Lei Complementar n 11.107, de 06 de abril de 2005. Dispóe sobre as normas gerais de contratação dos consórcios públicos. Diário Oficial, Brasília.

Brasil. (2007). Decreto $n^{\circ}$ 6.047, de 22 de fevereiro de 2007. Institui a Política Nacional de Desenvolvimento Regional. Diário Oficial, Brasília.

Brasil. (2011). PNDR: avaliaçâa da politica nacional de desenvolvimento regional. Brasília: Secretaria de Desenvolvimento Regional (SDR)/Ministério da Integraçấo Nacional.

Brasil. (2015). Lei $\mathrm{n}^{\circ}$ 13.089, de 12 de janeiro de 2015. Institui o Estatuto da Metrópole. Diário Oficial, Brasília.

Brasil, Ministério da Integração Nacional. (s/d). Política Nacional de Desenvolvimento Regional. Brasília: Secretaria de Programas Regionais (SPR)/Ministério da Integração Nacional.

Brasil, Ministério das Cidades (2008). Como anda Belo Horizonte. Brasília: Ministério das Cidades.

Carlos, A. F. (2001). A metrópole polifônica - poliorâmica. In M. A. Sposito (Org.), Urbanização e Cidades: perspectivas geográficas (pp. 59-72) São Paulo: Ed. Universidad Estatal Paulista (Edusp), Campus Presidente Prudente.

Castells, M. (1999). A era da informação: economia, sociedade e cultura. O poder da identidade. A sociedade em rede. Trad. R. V. Majer (4ª ed.). São Paulo: Paz e Terra.

Castells, M. (2000). A questão urbana. Trad. A. Caetano. São Paulo: Paz e Terra.

Censo Demográfico 2010. (2010). Características da população. Rio de Janeiro: Instituto Brasileiro de Geografia e Estatística (IBGE). Em http://cidades.ibge.gov.br/xtras/perfil. php?codmun $=330455$ 
De Mattos, C. (2204) Redes, nodos e cidades: transformação da metrópole latino-americana. In: Metrópoles: entre a coesão e a fragmentação, a cooperação e o conflito (pp. 157-196). São Paulo: Perseu Abramo / Rio de Janeiro: Fase.

Furtado, C. (1981). Pequena introdução ao desenvolvimento: enfoque interdisciplinar. São Paulo: Ed. Nacional.

Gouvêa, R. G. (2005). A questão metropolitana no Brasil. Rio de Janeiro: Editora FGC.

Haesbaert, R. (2002). Territórios alternativos. Niterói: Editora da Universidade Federal Fluminense / São Paulo: Contexto.

Instituto de Pesquisa Econômica Aplicada (IPEA). (2001). Caracterização e tendência da rede urbana do Brasil: redes regionais: Norte, Nordeste e Centro-Oeste. Brasília: IPEA/IBGE/ UNICAMP/IE/NESUR.

Lacoste, Y. (1988). A geografia, isso serve, em primeiro lugar, para fazer a guerra. Campinas: Papirus.

Ribeiro, L. C. de Q. (Org.). (2004). Metrópole: entre a coesão e a fragmentação, a cooperação e o conflito. In: L. V. Ribeiro, (Org.), Metrópole: entre a coesão e a fragmentação, a cooperação e o conflito (pp. 17-40). São Paulo: Fundaçấo Perseu Abramo / Rio de Janeiro: FASE.

Santos, M. (1991). Metamorfose do espaço habitado. São Paulo: Hucitec.

Santos, M. (1994). Técnica, tempo, espaço: globalização e meio técnico-científico-informacional. São Paulo: Hucitec.

Santos, M. (1994). O trabalho do Geógrafo no terceiro mundo. São Paulo: Hucitec.

Santos, M. (2002). Por uma Geografia Nova: da critica da geografia a uma Geografia critica. São Paulo: Ed. Universidad Estatal Paulista (EDusp).

Soja, E. (1993). Geografias pós-modernas: a reafirmação do espaço na teoria social. Rio de Janeiro: Jorge Zahar.

Sposito, M. E. (2001). Capitalismo e urbanização. São Paulo: Contexto. 
